\title{
THE RELATIVE DENSITIES OF ALKALI-METAL AMALGAMS AND MERCURY. II*
}

\author{
BY EDGAR C. BAIN AND JAMES R. WITHROW
}

This work (1) furnishes experimental confirmation of the deductions made upon this subject in the previous paper by one of the authors. ${ }^{1}$ (2) It supplies visual and analytical proof of the relative densities of solid alkali-metal amalgams and the liquid or solution phase in contact. (3) It demonstrates that solid amalgams are specifically lighter than their liquid contact phase in the case of Kerp's method of production as well as other methods. (4) It shows the real nature of "oily" and "pasty" amalgams. (5) It studies the maximum concentration of potassium in amalgams produced by electrolysis of saturated $\mathrm{KCl}$ solution. (6) It studies the preparation of calcium and ammonium amalgams.

\section{Historical}

The question of the relative densities of solid amalgams and their liquid amalgam phases in contact has attracted considerable attention. In describing a method for continuously producing solid amalgams, Kerp ${ }^{2}$ gives an illustration showing the final product as separating by virtue of difference in density into solid and liquid amalgam, and has labelled the lower phase in his illustration as the solid amalgam. This illustration has been reproduced by Abegg, ${ }^{3}$ This ignores the early work of Robert Hare ${ }^{4}$ which showed that ammonium amalgam when frozen floats on mercury. The later work of Shepherd, ${ }^{5}$ G. McP. Smith and Withrow, ${ }^{5}$ Whiting, ${ }^{7}$ and

*Contribution from the Chemical Laboratory of the Ohio State University.

1 Jour. Phys. Chem., 20, 529 (1916).

${ }^{2}$ Zeit. anorg. Chem., 17, 300 (1898).

${ }^{3}$ Handbuch anorg. Chemie., 2 II, 579 (1905).

"Edgar F. Smith: "Life of Robert Hare," page 313 (1917).

5 Jour. Phys. Chem., 7, 29 (1903).

6 Jour. Am. Chem. Soc., 29, 321 (1907).

7 Trans. Am. Electrochem. Soc., 17, 327 (1912). 
Withrow, ${ }^{1}$ furnishes reasonably clear evidence that at least some alkali amalgams appear lighter than mercury or their liquid phase in contact. The proof of this however is not complete, but the evidence seems strong. The object of this work was to acquire experimental proof.

Familiarity with the physical and chemical properties of two phase amalgams will soon convince one of the difficulty of solving this problem. Specific gravity values such as may be calculated from results recorded by $\mathrm{Maey}^{2}$ show the heaviest solid potassium amalgam to have the density of 13.3707 . Mercury has a density of 13.595. Maey's tables, when inspected and recalculated, show no solid amalgam heavier than liquid amalgam or mercury. While a continuation of the work of Maey is desirable, the purification and preservation of amalgam for specific gravity determinations presents numerous difficulties and is not a satisfactory method for solving the question before us, since a comparison is wanted merely between the solid phase and its liquid phase in contact. The industrial aspects of this problem have already been pointed out in the previous paper. ${ }^{3}$

\section{Amalgam Preparation}

The Shepherd method ${ }^{4}$ (G. McP. Smith and Withrow, ${ }^{5}$ Frank and Withrow ${ }^{6}$ ) was used with a porous cup and saturated solution of $\mathrm{KCl}$ as electrolyte. A $4 \times 8 \mathrm{~cm}$. porous cup was boiled in $\mathrm{KCl}$ solution until crystals formed on the inside which could be washed down. Two hundred grams of mercury were placed in the porous cup and some 20 to 30 grams of dry $\mathrm{KCl}$ scattered on its surface. Four to six amperes current flowed at five to seven volts for two hours. Con-

1 Loc. cit.

${ }^{2}$ Zeit. phys. Chem., 29, 128 (1899).

${ }^{3}$ Loc. cit.

${ }^{4}$ Jour. Phys. Chem., 7, 29 (1903).

${ }^{5}$ Loc. cit.

${ }^{6}$ Jour. Am. Chem. Soc., 42, 671 (1920). 
siderable heating took place and water was frequently added to the beaker, also, some $\mathrm{KCl}$ from time to time. Only a slight moistening of the $\mathrm{KCl}$ crystals in the cup took place due to endosmosis, in agreement with the observations of Frank and Withrow. ${ }^{1}$ When cooled somewhat from the temperature inside the cup, $70^{\circ}$ to $80^{\circ} \mathrm{C}$, the amalgam produced became very hard. When broken, it was an aggregate of many large crystal grains.

The directions of Smith and Bennett ${ }^{2}$ were followed in the preparation of sodium amalgam. The cathode and electrolyte container had a diameter of $5.5 \mathrm{~cm}$ and the anode presented approximately $8.5 \mathrm{sq} \mathrm{cm}$ surface and was quite close to the surface of the mercury. Two hours at a rate of four to six amperes with the cell surrounded by water in a larger glass dish produced a thick pasty or mealy product. The $\mathrm{NaCl}$ electrolyte soon reached a temperature of $70^{\circ}$ to $80^{\circ} \mathrm{C}$. and remained so. The amalgam became rigid when cooled to tap water temperature, but crumbled when handled.

This method was also employed to make some potassium amalgam. In 75 minutes a current of 4 to 6 amperes, at 7 to 9 volts, produced about 250 grams of amalgam which, when allowed to cool down slowly, formed very large cubes, some with $5 \mathrm{~mm}$ edges, and finally became rigid so that it was removed from the beaker in one block. The same cell was employed as in the case of sodium amalgam and will be known in this work as the standard cell, since all further work was done in it. During these preparations the salt crept and spattered up to the edges of the beaker and electrode supports, and down the outsides, but no great inconvenience resulted from this behavior. So long as the current did not increase above 5 to 6 amperes the bath did not reach boiling temperature, but it did evaporate considerably even at $85^{\circ} \mathrm{C}$.

\footnotetext{
1 Loc. cit.

${ }^{2}$ Jour. Am. Chem. Soc, 31, 301 (1909).
} 


\section{Determination of Relative Densities}

Since only relative densities and not absolute values were sought, consideration of a method involving the measurement of the volume of the amalgam produced from a known volume of mercury appeared worth while. Even the simplest apparatus for accomplishing this however, becomes evidently impracticable, because of difficulties from incorporation of moisture, salt, products of decomposition, and gases, which cannot be seen by the eye, in a given solid amalgam. Pipetting samples from various points in a mixture also was found unsatisfactory. When one considers that water may be drawn out along with mercury over which it has been poured, at a point several centimeters below the surface of the mercury, this last method, and ordinary separatory funnel principles cannot be used with certainty.

Apparatus.-For the examination of a mixture of solid and liquid amalgam free from contamination, a simple apparatus was designed. It consisted of cylinders of glass about $2.5 \mathrm{~cm}$ internal diameter with ground flanged tops, resurfaced by a fine abrasive and set into large plaster of paris blocks. One cylinder was cut off $5 \mathrm{~cm}$ from the top. The plaster of paris continued the surface of the ground flanged tops, for the cylinder flanges were inverted upon a glass plate, in casting, to form the bottom of the mold. When the ground flanges with their continuous plaster of paris surface of considerable area were placed to face upon each other, the two cylinders formed one continuous vertical cylinder reinforced at the flanged joint by a split plaster of paris block, sufficiently large so that sliding the one block upon the other had the effect of pulling the top section of the cylinder completely out of alignment and connection with the lower section. The lower cylinder was partially filled with plaster of paris to avoid the necessity of a large sample of material.

Procedure.-The process for using this device was also simple. The amalgam as produced was prepared as for analysis, then poured into the double cylinder and vigorously 
stirred up and down and then allowed to rest for a few minutes. The whole was then placed in a large evaporating dish and the top slowly and evenly slid upon the lower section. Then by holding the top and bottom plaster of paris blocks together the mass could be emptied from the top, then with the top removed the contents of the lower could be separately emptied into another container for examination and analysis. The physical nature, alone, of the top and bottom portions gave the solution of the problem.

The simplicity of this procedure eliminates tedious purifications, weighings, or volumetric measurements, which could easily be discounted. In each case, for additional information, the separated portions were analyzed. The method of analysis was that employed by Smith and Withrow (Loc. cit.)

\section{Experimental Data}

Typical analyses of upper and lower phase amalgams follow:

\begin{tabular}{c|c|cc}
\hline \hline Run No. & Amalgam & \multicolumn{3}{|c}{ Percent alkali } \\
alkali & \multicolumn{2}{c}{ Top } & Bottom \\
\hline 1 & $\mathrm{~K}$ & 1.48 & 1.46 \\
2 & $\mathrm{~K}$ & 0.76 & 0.47 \\
3 & $\mathrm{~K}$ & 0.74 & 0.49 \\
4 & $\mathrm{~K}$ & 1.12 & 0.49 \\
5 & $\mathrm{~K}$ & 1.18 & 0.86
\end{tabular}

In run No. 1, 800 to 900 grams of amalgam were made using the standard cell. In 90 minutes the mass in the cell seemed, somewhat thick and was poured out, washed in distilled water, dried with filter paper and put into the separator. The mass was so stiff when cool that it had to be scraped into the separator. After standing a short time the top was slipped over. The amalgam did not pour easily from either section. So far as could be judged the parts were alike in physical properties. The chemical analysis also showed them to be practically the same. The run had obviously been continued too long.

Run No. 2 was tmade under similar conditions but stopped 
much sooner. In the separator, the upper portion, after 4 to 5 minutes standing would just barely pour out, while the lower was very like pure mercury, except for a few rather small crystals. The chemical analysis showed the higher potassium content to be in the upper portion. In other words, the solid amalgam floated at the top and did not sink as shown in the record of Kerp and Abegg.

Run No. 3 used only slightly shorter time and it gave results similar to number 2. A rather longer run-4-was made and fifteen minutes allowed for flotation. In this case some 900 or $1000 \mathrm{~g}$ of mercury were used and when the top was slipped over on the lower cylinder block the crystals had matted so at the top that $327 \mathrm{~g}$ of crystals stuck in the top of the cylinder in a solid mass and from the space below this, and above the line of separation, there drained out $215 \mathrm{~g}$ of amalgam-liquid and solid. The portion in the lower block was entirely liquid so far as could be detected by pouring through a small aperture. This gave a striking visible demonstration that solid amalgam floats.

The portion of the upper section draining away from the solid mass of crystals at the top contained $0.59 \% \mathrm{~K}$. Chemical analysis again showed the higher $\mathrm{K}$ content amalgam to be in the upper section.

This run was so conclusive that a few attempts were made to get such a proportion of solid and liquid that the top would just be almost rigid and the lower part just all liquid. Two runs were made in which this situation was surprisingly nearly realized in that the contents of the upper part of separator would stand for several minutes rigid in the casserole like ingots of cast metal, while the lower portion was contaminated with only a few coarser crystals. Analyses were not made.

It was thought advisable now to make a few brief tests to see if sodium amalgam possessed similar properties. In general, sodium amalgam crystallizes in much smaller crystals and hence separation is slower. But substantially the results are the same as for potassium. Several runs were made 
with very satisfactory results, in that the top portion was quite thick with fine crystals.

\section{Verifleation of Results in the Case of the Kerp Method}

Although there was no reason whatever for suspecting that amalgams produced by the method just described, possessing peculiar reversals of properties at variance with those produced by the continuous method of Kerp, nevertheless, amalgams were made by the Kerp method and examined. As nearly as possible there were embodied in a complicated apparatus, all the features of Kerp's apparatus. In No. 5, with an E. M. F. of nearly 25 volts applied for 105 minutes nearly $1200 \mathrm{~g}$ of "slushy" amalgam were produced. Toward the end of the run the amalgam had a tendency to become more and more "oily" and "pasty" and adherent toward glass, and finally in the upper reservoir coarse crystals could be felt and at last some crystals clogged the fine aperture, whereupon the run ended. The amalgam was poured into the separator and stirred up and down vigorously, it being a few degrees above room temperature. In about twenty minutes it had cooled to room temperature and separation was made. The upper section slid out of the cylinder and stood up perfectly in the dish like cast tin. The lower section contained some few crystals but was essentially all liquid. Moreover, the upper portion had a potassium content on analysis which was markedly higher than the lower portion.

"Oily" and "Pasty" Amalgams.-The consistency of the more mobile of the amalgams is thick, oily or pastelike. To investigate this property some amalgams were made by short runs with the usual methods. They had just such characteristics and were permitted after washing and drying to stand some little time in closed vessels. Then the amalgams were subjected to filtration through chamois skin in a Gooch funnel and the filtrates examined in dry glassware. These were not "oily" or "pasty" to any extent but seemingly as mobile as mercury itself and only slightly adherent to glass. The filter when examined showed a compact deposit of very fine silver-white crystals of somewhat graphitic feel when 
rubbed between chamois. The yield was higher for the "thicker" amalgams.

A composite sample of filtrates showed a concentration of $\mathrm{Na}$ equal to $0.74 \%$. Sodium amalgams were chosen because they exhibit these characteristics best. Evidently "oily" or "pasty" amalgams are due to fineness of amalgam crystal grain.

The Maximum Concentration of Potassium Obtainable in an Amalgam Produced by Electrolysis of a Saturated $\mathrm{KCl}$ Solution.-The standard electrolytic cell was used and a heavy current passed through for various periods to see if a limiting value could be obtained. The first few experiments were sufficient to demonstrate that a cool electrolyte would produce a solid block of amalgam in the cell which could not of course be enriched to any extent on account of the impenetrability to newly discharged potassium ions. The solutions were permitted to boil under the heavy current, which took place at a temperature of $108^{\circ} \mathrm{C}$.

The results of these experiments were as follows:

\begin{tabular}{c|c|c|c|c}
\hline $\begin{array}{c}\text { Mercury, } \\
\text { grams }\end{array}$ & Voltage & $\begin{array}{c}\text { Current, } \\
\text { amperes }\end{array}$ & $\begin{array}{c}\text { Time, } \\
\text { minutes }\end{array}$ & $\begin{array}{c}\text { Percent, } \\
\text { potassium }\end{array}$ \\
\cline { 1 - 2 } 257.3 & $9-12$ & $12-15$ & 40 & 1.90 \\
207.4 & $9-12$ & $12-15$ & 85 & 2.00 \\
223.3 & $9-12$ & $12-15$ & 125 & 2.30 \\
279.0 & & $18-22$ & 145 & 2.14 \\
250.0 & & $18-22$ & 175 & 2.31
\end{tabular}

From these results it would seem that $2.31 \%$ potassium was a maximum. There is some loss inevitable in the washing of the amalgam and a safe estimate of the true concentration would be not greater than $2.35 \%$. This is very nearly the content of $\mathrm{Hg}_{s} \mathrm{~K}(2.38 \%)$ and shows that there is little likelihood that Kerp could have prepared a heavier amalgam.

In these runs it was noticed that after forty to sixty minutes the odor of evolved chlorine was not noticeable, and in a short time the vapors of the cell could be inhaled with no irritation and only a faint suggestion of the "hypo- 
chlorite" smell. It was suggestive of the smell of bleaching powder on the skin. It was thought that this cessation marked with reasonable closeness the saturation of the mercury with the alkali metal. Time did not permit investigating whether the alkali had run out or the hydroxyl concentration was taking care of the halogen at this point.

Ammonium Amalgam.-No one in the literature speaks of having obtained a crystalline ammonium amalgam, although Hare ${ }^{1}$ does refer to a frozen ammonium amalgam and Moissan ${ }^{2}$ says that ammonium amalgam produced and washed at low temperatures increases in volume from $15^{-20}$ times when the temperature rises from $-80^{\circ} \mathrm{C}$ to $+15^{\circ} \mathrm{C}$. We made a few runs to see if our technique would produce a crystalline amalgam electrolytically. The method used was much the same as that used by $\mathrm{J}$. Schroeder ${ }^{3}$ and was as follows: A block of $\mathrm{NH}_{4} \mathrm{Cl}$ (such as tinners use) was chiselled into a small cup and surrounded in a beaker with saturated $\mathrm{NH}_{4} \mathrm{Cl}$ solution. Mercury was placed in the cup-about 10 grams-and a platinum connector inserted. A large platinum electrode formed the anode. Voluminous ammonium amalgam was produced copiously with about 10 volts $\mathrm{E}$. M. F. It foamed up in a continuous, loose, ropelike mass. Much less mercury was used another time but the only difference noted was that the amalgam did not overflow the container. It was concluded, therefore, that a crystalline ammonium amalgam could not be produced by this method. The product appeared more like the "oily" or "pasty" amalgams just described than like crystalline amalgams.

Calcium Amalgam.-It was attempted to produce calcium amalgam by using a fairly strongly acid solution of calcium acetate and acetic acid with high current density. After some forty minutes the mercury showed some alkalineearth content, but it gave only a minute's effervescence in

\footnotetext{
1 Loc. eit.

2 Bull. Soc. chim. Paris, (3) 27, 717 (1902).

${ }^{3}$ Jour. prakt. Chem., 77, 271 (1908).
} 
acid solution. No trouble however was encountered from $\mathrm{Ca}(\mathrm{OH})_{2}$ precipitation as mentioned by other investigators. Carrying this out at low temperatures may solve this hitherto unsatisfactory preparation.

\section{Summary}

1. Solid alkali amalgams float on the "mother liquor," and do not sink in it as alleged by Kerp and Abegg.

2 . The method of Kerp produces sodium and potassium amalgams which are like amalgams produced by the other methods in that the solid is lighter than the liquid.

3. "Oily" and "pasty" consistencies in liquid (?) amalgams are due to fine crystals incorporated in the liquid.

4. By electrolysis potassium amalgams with concentrations up to $2.31 \%$ were obtained.

5. No difficulties except collection and preservation of a very spongy mass confront the investigator who would produce ammonium amalgam by electrolysis of $\mathrm{NH}_{4} \mathrm{Cl}$. Crystalline ammonium amalgams were not produced.

6. Acidified $\mathrm{Ca}\left(\mathrm{C}_{2} \mathrm{H}_{3} \mathrm{O}_{2}\right)_{2}$ with high current does not form a very satisfactory solution for the electrolyte of a calcium-amalgam cell, but yet does really produce a little of the amalgam, and offers hope for the elimination of the $\mathrm{Ca}$ $\left(\mathrm{OH}_{2}\right)$ evil.

The authors thank Mr. Lawrence E. Stout, Assistant in this laboratory for his help in assembling these notes.

Laboratory of Industrial Chemistry

Columbus, Ohio

July 25, 1921 